\title{
DISCURSOS E INTERPRETAÇÕES CONTEMPORÂNEOS EM TORNO DO PROFETA SÃO JOÃO MARIA ${ }^{1}$ \\ CONTEMPORARY DISCOURSES AND INTERPRETATIONS REFERRING TO PROPHET JOÃO MARIA
}

Tânia Welter*

\begin{abstract}
Resumo: Este é um estudo sobre os discursos contemporâneos a respeito de João Maria em Santa Catarina, Sul do Brasil. Partindo da noção de discurso como ação humana significativa, afirmo que os discursos a respeito de João Maria são construídos pelos joaninos a partir de sua cultura histórica (formada por valores, símbolos, imagens, personagens, eventos contextuais e um catolicismo difuso), possuem temporalidade, expressam algo e são disponibilizados para outras leituras e interpretações. João Maria é visto, neste trabalho, como evento fundante, em torno do qual gravitam muitos sentidos, identificado como Deus, Jesus Cristo, Profeta, Santo ou símbolo da luta pela terra. Legitimados, os discursos a respeito de João Maria apresentam-se como adequados na interpretação do mundo dos joaninos, no controle da indeterminação do mundo, para anunciar e acabar com o mal, reagir contra aquilo que não está de acordo com sua cultura, estimular a luta política ou anunciar o mundo desejado.
\end{abstract}

Palavras-chave: Discursos. Religiosidades. Santa Catarina. João Maria.

Abstract: This is a study on the contemporary discourses referring to Joao Maria in the state of Santa Catarina, southern Brazil. Taking as a reference the notion of discourse as a significant human action (Ricoeur), I defend that the discourses referring to Joao Maria are created by the joaninos (the people who recognize Joao Maria) through their historical culture (which is formed by values, symbols, images, contextual events and a diffuse Catholicism). These

\footnotetext{
* Professora na Universidade Federal da Fronteira Sul (UFFS), campus Chapecó SC.

E-mail: taniawelter@yahoo.com.br
} 
discourses also possess temporality, express something and are available to other analysis and interpretations. Joao Maria is seen, in this work, as a founding event around which gravitate many meanings, identified as God, Jesus Christ, a Prophet, a Saint or a symbol of the struggle for land. The legitimated discourses referring to Joao Maria can be understood as adequate in the joaninos interpretation of the world, in the control of the world indetermination, to announce and cease evil, to react against what conflicts their culture, to stimulate the political struggle or to announce the desired world.

Keywords: Discourses. Religiosity. Santa Catarina (Brazil). João Maria.

\section{INTRODUÇÃO}

Este trabalho busca observar os discursos contemporâneos em torno do Profeta São João Maria em diversas regiões de Santa Catarina para entender como se articulam com a vida e são reveladores de visões de mundo dos sujeitos discursantes. ${ }^{2}$

Para realização deste trabalho me inspirei e segui pistas de autores que levaram em conta a popularidade contemporânea de João Maria. ${ }^{3}$ Inspirada pela noção de discurso como ação humana significativa ${ }^{4}$, observei João Maria como "evento fundante" em torno do qual gravitam "múltiplos sentidos". 5

O interesse por João Maria foi despertado por fatos acontecidos em dois momentos da minha caminhada acadêmica: como pesquisadora, na Comunidade Cafuza de José Boiteux ${ }^{6}$, e como professora, na cidade de Lages/ SC. Os relatos orais (dos Cafuzos e dos estudantes) sinalizavam que João Maria tinha uma importância significativa para essas pessoas, as quais eram vinculadas a diversos contextos, condições econômicas ou credos religiosos e viam João Maria como alguém próximo, querido, aguardado e, muitas vezes, vivo. Percebi, também, que suas "orientações e ensinamentos" sobre a vida eram seguidos com seriedade e que suas "mensagens proféticas" eram frequentemente apropriadas para interpretação de eventos do passado e situações cotidianas, inclusive pelos estudantes universitários.

\section{ENCONTRANDO OS DISCURSOS A RESPEITO DE JOÃO MARIA: TRAJETÓRIA DA PESQUISA}

Inspirada por esses dados, realizei pesquisa específica objetivando conhecer os discursos a respeito de João Maria, na contemporaneidade, por sujeitos com recorte étnico diverso, com pertença religiosa diversa, residentes em contextos rurais e urbanos da região central de Santa Catarina. De forma 
específica, percebia a importância de buscar as referências contemporâneas (ostensivas e não ostensivas) ${ }^{7}$ a João Maria destes sujeitos, investigar as formas e argumentos utilizados por eles em seu reconhecimento, de que modo ele se inseria ao modo de vida dessas pessoas e o que adicionava ao mesmo. Segundo Weber $^{8}$, o reconhecimento é o aspecto central da legitimidade. Uma autoridade, ordem ou ação podem ser validadas aos olhos daqueles que lhes são sujeitos: pela tradição, em virtude de ligação emocional, pelo fato de uma crença racional ou por terem sido instituídas. Assim, por meio de atitude externa de imposição ou interna do sujeito, algo só é legítimo enquanto encontra reconhecimento por parte de alguém.

\section{Referencial teórico-metodológico}

Busquei referenciais que orientassem meu olhar sobre o objeto de pesquisa e que pudessem ampliar a perspectiva da abordagem empírica. Considerei que as categorias de discurso e interpretação de Ricoeur ${ }^{9}$, Velho ${ }^{10}$, e Geertz ${ }^{11}$ possibilitariam orientar e ampliar meu olhar sobre os discursos contemporâneos a respeito de João Maria.

Parti da noção de que todo discurso é uma ação humana significativa e possui referências ostensivas e não ostensivas. ${ }^{12}$ Aquilo que é explicitado pelos sujeitos é uma significação, não condiz mais com a situação inicial e, como significado revelado, se autonomiza e fica disponibilizado para outras leituras. Para Ricoeur, "há interpretação onde houver sentido múltiplo; e é na interpretação que a pluralidade dos sentidos torna-se manifesta". ${ }^{13}$ Toda interpretação, no entanto, tem por base um reservatório de experiências prévias. Ricoeur considera que a ação comunicativa é articulada a partir de normas, símbolos e signos próprios dos sujeitos, sem contar o não dito, como os preconceitos. ${ }^{14}$ Velho define isso como pré-texto (eu diria pré-discurso, no sentido mais amplo), ou cultura profunda, ou seja, as referências históricas e culturais que fundamentam a significação e interpretação dos sujeitos, definida aqui como cultura histórica. ${ }^{15}$

Além de explicitar significados produzidos e interpretados, o discurso abre a possibilidade de produção de significados novos segundo interpretações novas, inseridas em situações novas, envolvendo novos interesses, sempre no sentido de refazer as leituras possíveis segundo a cultura na qual estão inseridos o discurso e seu interlocutor. ${ }^{16}$ Assim, os discursos, além de explicitarem um mundo, mediarem a compreensão do ser-no-mundo ou compreensão de si, podem revelar um mundo desejado ou um poder-ser. 


\section{Definição dos sujeitos da pesquisa}

Diante de inúmeras dificuldades, optei por chamar de joaninos os sujeitos da pesquisa que reconhecem João Maria na contemporaneidade a partir de referenciais culturais, históricos, religiosos, políticos, turísticos, comerciais, entre outros. Quando necessário ou prudente especificar mais esse sujeito, utilizo o termo joanino acrescido de adjetivos como católico, devoto, pentecostal ou outro. Assim como em Dickie" ${ }^{17}$, esta "é uma abordagem processual em que os significados são pensados como integrantes das relações entre os sujeitos e, portanto, como sendo construídos e reconstruídos junto com a dinâmica destas relações". No caso deste trabalho, o acesso aos significados dá-se por meio dos discursos dos joaninos a respeito de João Maria.

Inspirada pelo sentido amplo possibilitado pela hermenêutica de Ricoeur ${ }^{18}$, "da práxis à história", considerei, neste trabalho, todas as práticas discursivas a respeito de João Maria, na forma oral, escrita, performática (ritual) e expressiva (iconográfica, musical, cinematográfica, cênica, televisiva, documental).

\section{Apresentando os dados de campo}

Percebendo o campo da pesquisa como o corte espacial de abrangência empírica e a pesquisa qualitativa como aquela que trabalha com atores sociais em relação e grupos específicos, realizei pesquisa de campo em diversos municípios de Santa Catarina entre 2004 e 2005. Posteriormente fiz pequenas incursões em campo, realizei assessorias a projetos institucionais e particulares, participei de formações e eventos e de rituais coletivos na Comunidade Cafuza (José Boiteux) e no Planalto Catarinense e orientei projeto de mestrado. Realizei pesquisa com sujeitos catarinenses residentes em comunidades, localidades, assentamentos da reforma agrária vinculados ao MST ou ao Incra, ou residentes na sede do município de Abdon Batista, Campo Belo do Sul, Capão Alto, Caçador, Campos Novos, Cerro Negro, Correia Pinto, Curitibanos, Fraiburgo, Frei Rogério, José Boiteux, Lages, Lebon Regis, Monte Carlo, São José do Cerrito e Santa Cecília, no estado de Santa Catarina, Brasil.

Os discursos dos joaninos a respeito de João Maria constituíram a base desta pesquisa, embora todos os demais dados coletados tenham sido importantes para complementar as informações e reconstituir até certo ponto o universo habitado por João Maria. Os joaninos, de ambos o sexos, com idade entre 10 e 98 anos, afirmaram ser católicos ou pentecostais; têm condições econômicas e profissões diversas, como estudantes, agricultores, comerciários, funcionários públicos, aposentados, professores (todos os níveis, inclusive universitários), advogados, vereadores, historiadores, escritores, jornalistas, 
radialistas e sindicalistas; e residem em contextos rurais e nas sedes dos municípios-alvo da pesquisa.

Sua origem étnica é também diversificada: alguns se consideram "de origem" 19 , outros, Cafuzos, quilombolas ${ }^{20}$, jagunços ${ }^{21}$, brasileiros, caboclos ou "de origem cabocla" 22 . Esse destaque se contrapõe a grande parte dos textos literários e não literários que vincula João Maria apenas ao segmento caboclo ou sertanejo.

Na questão específica do vínculo religioso institucional, grande parte dos joaninos declarou ser católico (cerca de 94\%), outra declarou ser evangélico ${ }^{23}$ (cerca de 6\%) vinculados a denominações religiosas pentecostais ${ }^{24}$, como: Igreja Assembleia de Deus, Igreja Obra da Palavra, Igreja da Redenção, Igreja Pentecostal Verdade Presente e Igreja do Evangelho Quadrangular. Apenas um entrevistado afirmou não ter religião ou ser "eclético", embora tradicionalmente estivesse vinculado à Igreja Católica.

Todos os pentecostais entrevistados afirmaram ter uma formação religiosa inicial católica e, em alguns casos, ter assumido posições de liderança laica (ministros, catequistas, capelães) antes de mudar para o vínculo atual. Isso leva a concluir que todos os entrevistados são cristãos, não havendo qualquer registro, por parte deles, de vínculo com outras religiões. Grande parte dos joaninos católicos não fizeram exatamente uma escolha pela religião, mas foram introduzidos diretamente nas práticas realizadas na vida familiar e comunitária. Essa capacidade para englobar o sujeito é uma das características observadas no "catolicismo tradicional". ${ }^{25}$ Já os joaninos pentecostais, frequentemente nascidos em lares católicos, optaram pela outra religião quando adultos.

\section{O MUNDO HIERÁRQUICO E ENCANTADO DOS JOANINOS}

\section{Mundo hierárquico}

Considero que o mundo dos joaninos está mais próximo de um holismo ${ }^{26}$ ou perspectiva hierárquica, em que o todo é mais importante que a parte e onde há mais pessoas que indivíduos, do que da perspectiva individualista, na qual o indivíduo é o valor supremo. ${ }^{27}$ Não estou afirmando com isso que o joanino não possui particularidades ou importância para o grupo, mas que este está articulado em torno de algo mais amplo - a família, o grupo doméstico, a comunidade, sendo incorporado neste "todo" a partir de sua participação nos espaços de sociabilidade, rituais religiosos (em destaque o batismo), organização do trabalho ou qualquer atividade em que a relação seja mais complementar do que individualista.

O mundo hierárquico dos joaninos é composto mais por grupos domésticos ou famílias extensas do que por famílias nucleares, visto aqui como 
o grupo constituído por pessoas com relações de consanguinidade, afinidade ou outra relação de parentesco que vivem numa casa. ${ }^{28}$

As redes de solidariedade e reciprocidade dos joaninos são acionadas sempre que surgem dificuldades concretas no trabalho cotidiano, nas dificuldades de saúde, dinheiro, transporte e outros. Isso não significa que essas redes funcionem a contento, e nem que as dificuldades sejam satisfatória e definitivamente solucionadas. Tomando como referência Mauss ${ }^{29}$, observamos que as trocas, teoricamente voluntárias, são, na realidade, obrigatoriamente dadas e retribuídas, porque o que trocam não são exclusivamente bens e serviços, mas colaborações entre coletividades, nesse caso, famílias ou grupos domésticos. Além da obrigação de retribuir, há a obrigação de dar e de receber. Deixar de dar ou recusar-se a receber equivale a recusar.

É comum em diversos países mediterrâneos, latino-americanos e também entre os joaninos a estratégia de estender a rede de parentesco através de outra rede - a rede de compadrio. ${ }^{30}$ A relação de compadrio, definida por adultos, é constituída a partir de rituais como o batismo e possibilita ampliar a rede de reciprocidade e solidariedade ${ }^{31}$ na linha horizontal (compadres e comadres recrutados na mesma camada social) e na linha vertical (recrutados em outras camadas). ${ }^{32}$ No primeiro caso, há uma tendência de escolha do compadre por relações afetivas e, no segundo, a possibilidade de um patrocínio econômico, político e social. O duplo batismo possibilita ampliar ainda mais esta rede, sendo recorrente a escolha dos compadres localizados na linha horizontal no batismo não eclesial e, na linha vertical, no batismo eclesial. Frequentemente toda família e amigos são envolvidos na relação de compadrio, mais cedo ou mais tarde, por meio de rituais de batismo, Primeira Eucaristia, Crisma ou Casamento.

\section{A vivência religiosa}

Observei que os joaninos vivenciam, de forma amalgamada, elementos próprios de várias religiões e rituais e elementos não institucionais. No caso dos joaninos católicos, a amalgação ocorre entre elementos e rituais próprios do catolicismo "popular", denominado também de tradicional ${ }^{33}$ ou rústico ${ }^{34}$, do catolicismo romano, catolicismo da libertação ${ }^{35} /$ catolicismo inculturado $^{36}$ e, mais raramente, catolicismo carismático. ${ }^{37}$ Os dois primeiros modelos de catolicismo estão na base daquilo que estou chamando como catolicismo difuso ${ }^{38}$, pois, embora suas raízes estejam na Idade Média Europeia, influenciaram profundamente a sociedade brasileira e catarinense e se apresentam, ainda hoje, como o principal referencial religioso dos joaninos. As duas outras formas de catolicismo (catolicismo da libertação e carismático) têm como marcos o Concílio Vaticano II, o diálogo com o "mundo dos pobres" (no caso 
da Teologia da Libertação) e com o "mundo moderno" (no caso da Renovação Carismática). ${ }^{39}$ Embora não tenha percebido grande influência do segundo modelo no catolicismo difuso, os joaninos foram muito influenciados pelos padres ligados à Teologia da Libertação no reconhecimento de João Maria. ${ }^{40}$

Em termos históricos, é possível afirmar que o catolicismo catarinense foi formado, ainda no período colonial, a partir dos conteúdos devocionais do catolicismo português. Estes conteúdos foram mesclados, no território catarinense, primeiramente com as "populações nativas" (indígenas, descendentes de africanos e caboclos) e, posteriormente, com as dos "colonos de origem". ${ }^{41}$ Neste processo, elementos da religião institucional foram reinterpretados, transformados e adaptados pelas populações de acordo com as especificidades de cada grupo e contexto. Dessa maneira, as práticas do catolicismo, embora semelhantes na base, foram transformadas no contexto. Esse processo e a falta de uma presença mais efetiva da Igreja teriam gerado um catolicismo de caráter leigo, marcado pelo culto aos santos e a outros habitantes a quem se atribuem poderes taumatúrgicos (João Maria, por exemplo), devoções penitenciais, procissões, romarias, festas, bênçãos, curas e proximidade com elementos naturais como grutas, fontes de água e remédios naturais. Essa situação qualificaria o que Monteiro ${ }^{42}$ denominou como "impregnação religiosa na vida quotidiana" ou "inexistência de demarcação entre os fenômenos da natureza, da sociedade e do sobrenatural" viabilizada por uma concepção de mundo cosmicizante.

Os joaninos explicam que os elementos que caracterizam a "religião dos antigos" ou "fé dos antigos" foram transmitidos oralmente aos demais. Quanto à fé, explicam: “é a mesma fé da Igreja, a diferença é só no praticar a fé". Ressaltam, também, que algumas práticas foram criadas, recriadas e vividas nas comunidades ${ }^{43}$, mas que sua presença é, muitas vezes, criticada pelo clero local. Em grande parte das localidades observadas, a hierarquia eclesial (tanto sacerdotes católicos, quanto pastores evangélicos) está muito ausente no cotidiano das comunidades e, em alguns casos, sua presença não é muito apreciada. Além disso, geralmente são as pessoas que constroem e administram as capelas ou casas de oração. $\mathrm{O}$ que pretendo destacar aqui, portanto, é que a religiosidade dos sujeitos é vivenciada para além da hierarquia eclesial e que nem sempre há acordo ou harmonia na relação da comunidade com esta.

\section{JOÃO MARIA E OS RITUAIS RELIGIOSOS}

\section{João Maria: a salvação e a purificação}

João Maria está inserido em quase todos os rituais da "religião dos antigos". ${ }^{44}$ É recorrente entre os joaninos a utilização de diversos batismos, nos quais João Maria opera. Embora não lhes seja uma característica específica, 
os joaninos batizam a criança assim que nasce, em casa ou em outro local, na presença de familiares e padrinhos numa cerimônia geralmente coordenada pelo "apresentador". ${ }^{45}$ É uma cerimônia simples, sem necessidade de festa ou presentes, objetiva batizar e "salvar a alma" da criança e, dessa maneira, possibilitar a ela uma proteção divina, ou seja, apresenta-se como rito propiciatório porque, por meio dele, Deus se torna propício para ajudar e proteger a criança batizada.

Perguntados sobre como é o procedimento do batizado, relatam que o "apresentador" pede aos padrinhos para segurar a criança, enquanto diz as seguintes palavras, aspergindo sobre ela a água benta com um ramo de arruda (ou outro ramo verde): "eu te batizo fulano(a) de tal, com o nome de Deus, em nome do Pai, do Filho e do Espírito Santo, amém!". No caso dos joaninos, é frequente a incorporação do nome de São João Maria nesse texto.

O batismo não eclesial envolve todos os interessados, tendo como oficiantes centrais os padrinhos, os quais geralmente são escolhidos na rede social da família e a partir de critérios próprios, mas frequentemente sem limite numérico, restrições à idade, condição econômica ou ao vínculo de parentesco, sendo possibilitada a participação de crianças, pessoas com outros vínculos religiosos ou sem religião e até de santos, como João Maria. ${ }^{46}$ As crianças participam de forma semelhante aos adultos, assumindo o mesmo compromisso que um adulto assumiria com o afilhado e a família deste, como mencionei anteriormente.

O rito do batizado não eclesial entre joaninos é frequentemente realizado em casa ou em fontes de água de João Maria. A água é um dos elementos centrais no ritual do batismo e, para ser usada, deve estar benta, ou seja, tornada sagrada. ${ }^{47}$ Para os joaninos, o processo de consagração da água pode ocorrer de duas formas: 1) pegar água comum e solicitar uma benção de uma autoridade eclesiástica ou, mais frequente, 2) coletar água na fonte de João Maria e, neste caso, seu processo de consagração já terá ocorrido porque, para os joaninos, tudo o que foi tocado ou pertenceu a João Maria possui caráter sagrado. A água retirada da fonte de João Maria é denominada pelos joaninos como "água santa" e possui, para eles, capacidades curativas, além de ter uma "relação simpática" com João Maria ${ }^{48}$ e, portanto, embora retirada de seu habitat, mantém consigo parte de João Maria e é detentora de seu poder.

Ao passar pelo processo de consagração, a água fica habilitada para purificar e promover a salvação das pessoas por meio do batismo ou de outro ritual, curar doenças (internas e externas), proteger espaços e pessoas, fertilizar a terra, expiar os males e propiciar proteção divina. Muitos relatam o desejo e grande esforço empreendido para conseguir a "água santa", sendo comum buscá-la em longas distâncias. ${ }^{49}$ Diante da dificuldade de obtenção de "água santa" e de sua preciosidade, muitos joaninos misturam uma pequena 
quantidade dela com água corrente até obter o volume desejado, operando uma nova etapa no "processo simpático".

A partir do relato anterior, é possível observar uma série de simbologias relacionadas à "água santa", utilizada também no batizado não eclesial: bem sagrado, fonte de cura, retira o mal, propicia proteção divina, coloca o sujeito em contato com o divino, purifica a alma e promove a salvação. Essa água é assumida como dádiva de João Maria por meio da qual seu poder se difunde para as pessoas, balizando suas vidas e propiciando-lhes uma vida boa e purificando seus males.

Apenas após ter sido estabelecida a "relação simpática" com João Maria por meio da "água santa" utilizada no ritual do batismo não eclesial, e quando as condições para o batizado eclesial forem reunidas, ele pode ou não ser promovido na Igreja. ${ }^{50} \mathrm{O}$ rigor do cerimonial eclesial não inviabiliza uma participação diferenciada das pessoas durante o batismo na Igreja. Visto de forma comparativa, é possível perceber que, diferente do rito eclesial, o batismo não eclesial é mais dinâmico, pois possibilita uma maior participação de padrinhos, colocando em destaque pessoas que ficariam em segundo plano no rito eclesial (mulheres e crianças) e, portanto, provoca uma inversão na ordem do cerimonial. ${ }^{51}$ A participação de crianças, portadores de necessidades especiais, adultos não católicos e santos como padrinhos são também formas de transgressão ao modelo institucional. Na questão da legitimação das relações horizontais e verticais do compadrio, o batismo eclesial pode ser complementar ao não eclesial. É neste que João Maria atua como integrador horizontal.

Independente da forma, eclesial ou não eclesial, o batismo é uma das formas de incorporar o indivíduo em redes sociais, tanto pessoais como institucionais. Possibilita, também, ampliar as redes de parentesco para outra rede, a do compadrio, e, com isso, estabelecer novas ou ampliar as já existentes relações de confiança, de solidariedade e reciprocidade.

Há um outro tipo de batismo, no entanto, denominado por mim de batismo de cura. Embora seja chamado de batismo pelo joaninos, o batismo de cura não tem as mesmas implicações sociais que o batismo não eclesial. É, também, um rito de purificação, mas é, acima de tudo, um ritual de cura, frequentemente operado por João Maria.

Dentre os rituais de batismo observados entre os joaninos, foi possível constatar a importância fulcral de João Maria na introdução de indivíduos nas diversas redes sociais, na legitimação do batismo horizontal, na ampliação das redes de parentesco e de reciprocidade por intermédio do compadrio, nos procedimentos de cura a partir da "água santa" e na sua atuação como padrinho. 


\section{João Maria em rituais coletivos}

A maioria dos católicos catarinenses tem o hábito de participar de forma coletiva em rituais religiosos que, apesar de comporem o conjunto de práticas devocionais católicas, adquirem, no contexto, características próprias, na forma, periodicidade, espaço e coordenação. Tendo como pano de fundo o desejo de sentir-se mais seguro e, de certa forma, domesticar aquilo que é indeterminado no mundo, os joaninos promovem e participam frequentemente de rituais que são realizados em momentos próprios, com data pré-definida, e de outros que são realizados sem combinação anterior e ocorrem somente numa eventualidade, como adoecimento, morte, nascimento e visita. Estes rituais são, em grande parte, coordenados por lideranças religiosas laicas, ocorrem sem participação eclesial e recorrem a João Maria. Trata-se, por exemplo, da reza de terço (com orações cantadas muitas vezes), realização de procissões, via sacra ${ }^{52}$ e novenas. ${ }^{53}$

Destaco primeiramente os rituais penitenciais que "objetivam auxiliar as almas a encontrar o caminho", como, por exemplo, a "Recomendação de almas" realizada preferencialmente durante a Quaresma ou a participação em eventos religiosos no "dia das almas" ( 2 de novembro). Nesses eventos, é central a preocupação com as almas dos parentes e, frequentemente, é solicitada sua presença para proteger os vivos no cotidiano.

Outro ritual religioso, classificado como penitência pelos joaninos e conhecido como Reza do 25 , é realizado anualmente no dia 25 de março, geralmente coincidindo com o período da Quaresma, em diversas localidades do município de Campo Belo do Sul. ${ }^{54}$

Observei diversos eventos desta natureza e considero importante ressaltar algumas características desses rituais, como sua capacidade adaptativa, sua dinamicidade interna, a ampla participação do público interessado (inclusive crianças e portadores de necessidades especiais). Outros aspectos relevantes desses rituais: o reforço dos laços de sociabilidade e das redes de reciprocidade, estímulo de valores sociais fundamentais como honra, hierarquia, solidariedade, respeito e justiça. Além disso, esses rituais configuram-se como espaços para desenvolvimento e exercício de liderança e de talentos individuais, para ostentação e exercício da política, de reforço da tradição religiosa, do exercício da religiosidade não institucional e, por último, mas igualmente importante, para contato com o sagrado e com João Maria.

Outro aspecto é a destacada capacidade dos joaninos de transposição de supostas fronteiras entre entidades (Deus, diabo, santos, almas), espaços (sagrados e não sagrados) e ritos (domésticos, institucionais), possibilidade de proteção divina por meio dos mediadores, além de apropriação e expressão de uma infinidade de crenças e simbologias provenientes de diversas organizações religiosas. Outro aspecto a ser destacado é a impregnação da religiosidade 
na vida cotidiana ou que esses rituais acontecem num mundo impregado da simbologia religiosa.

Por fim, estamos diante de rituais que misturam elementos que, por um lado, legitimam a instituição e, por outro, reivindicam uma espécie de "poder local" sobre a esfera do religioso e do divino. A convivência destas atitudes resultam num amálgama que define uma religiosidade própria que não pode ser classificada dualisticamente.

\section{João Maria e os procedimentos de cura}

Assim como em outros lugares do Brasil, em Santa Catarina encontrei diversos especialistas conhecidos como curandeiros, benzedores ${ }^{55}$, puxadores de reza, adivinhos, penitentes e capelães.$^{56}$ Embora se afirme que se estabelece uma hierarquia entre os especialistas, alguns dedicados mais às atividades religiosas e outros às práticas curativas, é mais comum encontrar os que assumem diversas funções e especialidades. Como mencionei anteriormente, o batismo de cura não requer um especialista dos tipos mencionados acima, mas um que conheça os procedimentos de cura associados a João Maria. Nada impede, no entanto, que o apresentador seja também um benzedor(a) ou capaz de outra especialidade.

Os benzedores costumam utilizar diversos procedimentos de cura diante de problemas de saúde em humanos e animais, malefícios sem origem nítida, problemas concretos e como forma de proteção de um espaço (casa, instituição, plantação). Esses procedimentos de cura vão desde benzimentos (utilizados em caso de doenças físicas, machucados, doenças psíquicas, doenças dos nervos), utilização de medicamentos naturais (ervas ou remédios naturais), até procedimentos rituais e pouco explicitados para enfrentar e proteger dos malefícios como quebranto, mau-olhado, susto, feitiçaria e bruxaria. Além de curar, estas pessoas também benzem e abençoam casas, construções, plantações, reuniões e até viagens. Estes especialistas podem estar vinculados e serem procurados por pessoas com vínculos religiosos diversos, inclusive não católicos.

O especialista que se dedica a produzir e orientar o uso de medicamentos naturais para problemas diversos é denominado de curandeiro ou "remedeiro". O primeiro difere do segundo apenas na sua profissionalização - enquanto o primeiro realiza um trabalho voluntário, o segundo geralmente se profissionaliza nele, sendo recorrente sobreviver da venda dos medicamentos naturais que produz ou de consultas. O procedimento, tanto de um quanto do outro, no entanto, geralmente vem acompanhado da utilização de procedimentos religiosos e aqui, de novo, João Maria é presença recorrente. 
João Maria é reconhecido pelos joaninos como exímio benzedor e profundo conhecedor de ervas medicinais e de procedimentos de cura. Algumas pessoas afirmam ter recebido de João Maria o conhecimento dos procedimentos de cura e que, em alguns casos, o próprio João Maria era convocado pelos humanos para auxiliar nos procedimentos, fornecendo mais eficácia ao procedimento. Esses conhecimentos são apropriadas pelos joaninos e adaptados às situações contemporâneas, como problemas de saúde, dicas sobre uma boa produção agrícola ou para combater pragas, como enfrentar e prevenir dificuldades, entre outros. $\mathrm{O}$ discurso sobre estas receitas geralmente é acrescido de outros elementos, como valores éticos e religiosos, e sua reprodução serve para transmissão destes princípios. Esta é outra mostra de que há uma impregnação de valores religiosos no cotidiano dos joaninos (noção desenvolvida por Monteiro ${ }^{57}$ e Serpa $^{58}$ ).

\section{A cruz de João Maria}

Os joaninos afirmam que, quando João Maria peregrinou na terra, tinha o hábito de plantar uma cruz de cedro em cada local que pousava ou chegava, fundando religiosamente o lugar pela plantação da cruz.

Afirmam também que, por sua capacidade divinizadora, isso fazia com que o local e as pessoas ficassem protegidos diante das catástrofes naturais ou de quaisquer dificuldades. Assim, a cruz de cedro tornou-se um símbolo de João Maria e passou a ser plantada por católicos e pentecostais diante de casa ou em qualquer espaço que se queira protegido. Após ser plantada, frequentemente a cruz brota e transforma-se novamente em árvore, mas as pessoas referem-se a ela ainda como a "cruz de João Maria". Os devotos afirmam que o brotamento é indicativo de que João Maria abençoou a casa/espaço e aqueles que ali estão.

A cruz, de maneira geral, é reconhecida como um dos símbolos religiosos mais importantes e usada, especialmente por católicos, como forma de proteção contra qualquer perigo ou ameaça. ${ }^{59}$ No caso da "cruz de João Maria", denominada muitas vezes como "Santa Cruz", mais do que um símbolo religioso, é demonstração da fé em João Maria, mas também presença de sua proteção contra perigos externos. Além de proteger a pessoa e a casa, a cruz de cedro identifica também o devoto de João Maria. Cruzes de cedro são plantadas também em eventos coletivos e anuais como a Romaria da Terra, realizada em Santa Catarina desde 1986, coordenada pela Comissão Pastoral da Terra (CPT) ${ }^{60}$ e, neste caso, possui forte conotação política. A plantação da cruz de cedro é realizada durante o ritual ecumênico. Ocorre desde a primeira Romaria da Terra e é justificada da seguinte maneira pelas lideranças do movimento: "plantando a cruz, o povo lembra João Maria e recorda os mártires na luta pela terra". ${ }^{61}$ 
O importante a destacar aqui é que a plantação da "cruz de João Maria", além de ser outra tentativa (pessoal ou coletiva) de controlar a indeterminação do mundo ${ }^{62}$ porque possibilita criar uma aura de proteção ao ambiente e às pessoas, promove uma espécie de sacralização do lugar. Tanto a água como a cruz de cedro são "elementos simpáticos" de João Maria. São, portanto, veículos de seu poder, seja ele de cura, proteção contra os males ou o mal, e a favor dos joaninos nas suas lutas políticas. A cruz traz a proteção para o espaço e para as pessoas no espaço definido como de abrangência do efeito da cruz. Assim, a cruz traz de João Maria, tornando-o presente, proteção, devoção e força política.

Nesta parte tentei demonstrar como o mundo dos joaninos foi definido como hierárquico porque há mais pessoas que indivíduos e estas são incorporadas na totalidade, também, por meio de rituais religiosos. O cotidiano é impregnado de uma visão de mundo religiosa, possibilitando o exercício de práticas que não obedecem necessariamente aos cânones da instituição religiosa. Permite, também, o exercício da liberdade de crença, sem deixar de reconhecer a autoridade institucional. É a cultura católica que está na base do mundo dos joaninos e que, como observei, pode estar difusa e profunda, mas disponível para ser apropriada a qualquer momento. Dessa maneira, pode-se considerar a existência de um mundo com valores religiosos e um mundo religioso não vinculado necessariamente a uma organização religiosa.

Este mundo é encantado por João Maria, que opera em rituais e no controle da "indeterminação do mundo" 63 e é constantemente apropriado também como referente ético, prático e religioso.

\section{RECONHECIMENTOS DE JOÃO MARIA}

Os discursos dos joaninos a respeito de João Maria são percebidos como ações significativas, formulados a partir de referências próprias do sujeito (valores, símbolos, preconceitos) e da interlocução. Os discursos são interpretações, embora muitas vezes estes afirmem estar reproduzindo o discurso "original" e servem como mecanismos de legitimação destes discursos e, consequentemente, de João Maria. Ao apropriá-los, os sujeitos transformam estes discursos legitimados em mecanismos de legitimação dos discursos dos próprios sujeitos. Assim, ao mesmo tempo em que legitimam os "discursos de João Maria”, são legitimados por eles. Frequentemente, os discursos se autonomizam das referências ostensivas e tornam-se disponíveis para novas interpretações.

João Maria é reconhecido como divindade pelos joaninos a partir de critérios como: características físicas e modo de vida, família, capacidades especiais, missão na terra e atribuída imortalidade. Os sujeitos o percebem 
como uma entidade ambivalente (humana e não humana ao mesmo tempo) e imortal. Ao afirmar que ele não pode ter morrido porque é "um santo homem" ou "profeta de Deus", estão reforçando sua noção de que João Maria é uma entidade com potencialidades semelhantes a Jesus Cristo e Deus, ou, como sugere Mourão ${ }^{64}$, um homem que alcançou a perfeição da condição humana, afastou-se dos males, purificou-se e conquistou definitivamente a vida. Nessa conquista, digo eu, incorporou todas as qualidades dos seres sagrados: como capacidade de onisciência, onipotência, onipresença, invisibilidade, inatingibilidade, longevidade ou imortalidade, capacidade de mudar de forma, ficar invisível, levitar ou locomover-se sobre as águas, modificar o estado das coisas e interferir na vida das pessoas, conhecer "o coração dos homens", punir pecadores, limpar aquilo que está sujo ou tornar sagrado aquilo que toca.

O reconhecimento de João Maria como santo é o mais recorrente entre os joaninos católicos e pentecostais, denominado como São João Maria, São João Maria do Agostinho ou Profeta São João Maria. A construção deste, como indivíduo venerável, é elaborada a partir dos elementos selecionados pelos joaninos como qualidades, atitudes e capacidades especiais.

Embora com diferenças, grande parte dos discursos identifica João Maria como profeta e santo ao mesmo tempo. Dessa forma, demonstra outra das suas ambivalências, o que me autoriza a falar em multivalências, ou seja, com possibilidades múltiplas de identificação a partir das mesmas capacidades: enquanto alguns o identificam com Deus, outros com Jesus, há aqueles, ainda, que o identificam como um profeta enviado de Deus.

A partir da observação de obras arte, instalações, acervo de museus, grutas/santuários, músicas, poesia, dança, peças teatrais e cinema, foi possível constatar que os discursos expressivos ${ }^{65}$ apresentam duas caracterizações de João Maria vinculadas às temporalidades diferentes: como liderança religiosa e política (do passado) ou como santo (presente). João Maria é apresentado, no século XIX, como reconhecido monge peregrino com capacidade profética e milagrosa. Num segundo momento, João Maria é reconhecido como liderança dessacralizada de um movimento social que culminou numa sangrenta guerra e na derrota dos protagonistas. Alguns discursos ressaltam também as repercussões dessa liderança do passado nas lutas atuais por justiça social, nas quais João Maria aparece configurado como símbolo de luta dos "excluídos".

João Maria foi incorporado também num projeto político e governamental, de resgate da memória do Contestado. A ideia do projeto surgiu em 1980 a partir do então candidato ao governo do estado de Santa Catarina (Esperidião Amin) que buscou na Guerra do Contestado e nos valores do "vencido", a inspiração para criar aquilo que chamou de identidade catarinense. ${ }^{66}$

São discursos que se constroem, não pelos joaninos, mas por interesses diferenciados em usar, seja a imagem de João Maria, seja a de sua vinculação com a Guerra do Contestado, com diferentes finalidades. A confusão que 
foi apontada antes entre Guerra do Contestado e Guerra Santa aparece aqui em toda sua clareza: é na manipulação da santidade de João Maria como santo ou profeta, como benzedor ou líder político/religioso - que é construída a legitimidade de projetos políticos e empresariais. Diferente das práticas cotidianas dos joaninos, estas práticas não se pautam pela fé ou pela religiosidade, mas por metas ou bandeiras que tratam João Maria como um personagem especial, mas não o equiparam a um santo. Antes, retiram-lhe a santidade explicitamente, em alguns casos, manipulando, no entanto, sua legitimidade como santo entre a população (o Projeto de Amim e a Igreja Progressista); manipulam-na simplesmente em outros (os empreendimentos turísticos); em outros ainda, usam-na de forma ambígua, como em projetos artísticos que têm a finalidade de ressaltar bandeiras políticas de esquerda (os filmes, documentários e peças de teatro).

\section{CONSIDERAÇÕES}

Interessada em interpretar os discursos contemporâneos a respeito de João Maria, busquei referenciais histórico-culturais e teórico-metodológicos que pudessem contribuir neste processo. Considerei que categorias como discurso, interpretação, mundo, calendário vivencial, religiosidade, devoção e campesinidade poderiam orientar e clarear os caminhos da interpretação. Assumi discurso como ação humana significativa no sentido amplo possibilitado pela hermenêutica de Ricoeur - da práxis à história, ou seja, na forma oral, escrita, performática e expressiva.

Observei que os discursos acadêmicos e não acadêmicos insistiam na afirmação de que o João Maria, que habitava a contemporaneidade, era o líder religioso surgido no Brasil no século XIX, denominado como monge/ profeta que teria sido mantido no imaginário "popular" especialmente por meio de lendas, histórias e mitos. Afirmavam também que este teria inspirado a organização de um movimento de "rebeldia" de sertanejos pobres contra as elites locais e nacionais no início do século XX, denominado oficialmente como Guerra do Contestado. Estes autores informavam ainda que, após o término da guerra, João Maria teria passado por um processo de canonização "popular" e continuava sendo vinculado a uma religiosidade tradicional, rústica e "popular" de populações pobres, ignorantes, neste caso "os caboclos", cujos aspectos marcantes eram sua impregnação na vida cotidiana, proximidade com a natureza, práticas mágicas e autonomia da instituição religiosa (neste caso Católica).

A pesquisa empírica mostrou-me que o vínculo atual das populações com João Maria é muito mais amplo e complexo do que santo devotado pela população pobre. Este é legitimado por joaninos com vínculos econômicos, 
étnicos, culturais e religiosos diversos. Além disso, é legitimado por lideranças de movimentos sociais que buscam nele o fortalecimento de lutas políticas, especialmente pela terra. Sua imagem e símbolos são também utilizados com fins comerciais e turísticos. Todavia, de forma mais fundamental, este é caracterizado com grande especificidade e contextualidade e relacionado aos referentes culturais e históricos dos joaninos. Essas relações são fundamentais para perceber que, mais do que lenda ou mito, João Maria é uma referência para os sujeitos para explicitar, em ação discursiva significada, elementos cruciais de seu mundo. Constatei que os discursos a respeito de João Maria são construídos pelos joaninos no presente, estão referenciados em sua cultura histórica, servem como reforço dos valores sociais hierárquicos e como forma de encantamento do mundo. Seu vínculo com a natureza legitima, para os joaninos, uma campesinidade, que persiste mesmo em contexto urbano.

A descrição dos diversos aspectos que compõem o mundo religioso dos joaninos indicou uma impregnação da vida cotidiana neste e uma concepção de mundo cosmicizante. Além de o mundo religioso estar impregnado da vida cotidiana, constatei que o mundo dos joaninos está integrado com uma cultura religiosa (especialmente católica) difusa e profunda, mas disponível para dar sentido para o mundo a qualquer momento. Assim, tanto seu mundo possui valores religiosos, quanto o mundo religioso está impregnado da vida cotidiana e não há uma separação nítida entre o que é o não religioso. Isso estaria possibilitando o exercício de práticas diversas, inclusive aquelas que não obedecem necessariamente aos cânones da instituição religiosa, o exercício da liberdade de crença, sem deixar de reconhecer a autoridade institucional.

Constatei também que o mundo religioso dos joaninos está habitado por almas, santos, Deus, diabo e lideranças laicas, mas também, de forma significativa, por João Maria, que opera junto aos católicos e pentecostais no controle de indeterminação do mundo e é constantemente apropriado também como referente ético, prático e religioso.

Observando os discursos dos joaninos, constatei que João Maria está inserido em sua cultura histórica e, a partir dela, é apropriado na contemporaneidade. Os joaninos referem-se a João Maria a partir daquilo que conhecem e vivem, e o ambiente da interlocução apresentou-se como adequado para transmissão também de mensagens significativas. Além disso, embora muitos afirmem que os discursos são "de João Maria”, estes são atribuídos a ele pelos joaninos e, portanto, são sempre interpretações, de segunda ou terceira mão, como diria Geertz. ${ }^{67}$ A base do discurso é o conhecimento familiar daquele que exprime o discurso, mas, a partir daí, novas interpretações são formuladas.

De uma forma ampla, João Maria foi percebido pelos joaninos como um sujeito simples, despojado e desapegado de valores "mundanos". Vivia só, embora possuísse irmãos e irmãs, era detentor de muitas capacidades especiais, mas marcadamente era visto como próximo e comprometido com os sujeitos, 
especialmente empobrecidos. Além disso, os discursos evidenciam outras características de João Maria, em sua trajetória na terra, como capacidade de onisciência, onipotência, onipresença, invisibilidade, inatingibilidade, longevidade ou imortalidade, ou seja, possuía capacidade de mudar de forma, ficar invisível, levitar ou locomover-se sobre as águas, modificar o estado das coisas, interferir na vida das pessoas. Essas capacidades teriam sido possibilitadas especialmente por sua condição de enviado de Deus na terra, somente esta posição o habilitaria a premiar os puros e justos e punir os injustos, avarentos e egoístas. Os joaninos indicam outras capacidades em João Maria que o aproximam da posição de benzedor, milagreiro, guia, profeta, apóstolo, divindade, embora se diferençasse dele por sua característica humana.

Sua ambivalência o aproximou da condição de outro enviado de Deus na terra, Jesus Cristo. Comparando os discursos dos joaninos a respeito de João Maria e de Jesus Cristo, foi possível constatar que ambos são vistos como humanos e não humanos ao mesmo tempo, tiveram uma trajetória difícil, possuem conhecimento religioso profundo e sensibilidade para "conhecer o coração das pessoas". Sua condição de penitente pelo bem da humanidade o habilitou para assumir a condição de salvador, equivalente a Jesus Cristo.

Sua caracterização também como profeta ético e exemplar me permitiu afirmar sua multivalência. Segundo os joaninos, o dom de Deus o habilitou a anunciar os desígnios divinos, ensinar e aconselhar o comportamento não aprovado por Deus e, como divindade, punir os pecadores e premiar os justos, trazer a vitória do bem contra o mal, corrigir a imperfeição do mundo, salvar os homens pelas suas penitências e permitir o advento do paraíso terrestre, e, dessa maneira, possibilitar que o apocalipse se complete.

Entre os joaninos católicos, João Maria é reconhecido como santo e devotado de forma semelhante aos santos canonizados pela Igreja Católica, mas opera também entre pentecostais no controle da indeterminação do mundo. Os elementos de sua sacralidade estão em sua condição de peregrino penitente, poder milagroso de cura, atribuída imortalidade, comprometimento com os necessitados, capacidade de conhecer o "coração dos homens". Sua condição de santo o habilitaria a punir pecadores, limpar aquilo que está sujo e tornar sagrado aquilo que toca. Os objetos que teriam pertencido a João Maria ou tocados por ele teriam sido embebidos de sua consagração e apresentam-se como habilitados para purificar e promover a salvação, curar doenças (internas e externas), proteger espaços e pessoas, fertilizar a terra, expiar os males e propiciar proteção divina. Portanto, é santo protetor e purificador. Como indivíduo venerável, alcançou a perfeição da condição humana, a condição de purificado e conquistou definitivamente a vida e, portanto, é argumento de legitimação dos devotos frente à hierarquia católica. A cruz de cedro e a "água santa" foram os símbolos atribuídos a João Maria mais destacados neste trabalho e são utilizados, inclusive, por pentecostais. Outros símbolos 
como orações, objetos pessoais, "medidas do santo" e imagens são também apropriados.

Os dados da pesquisa possibilitaram afirmar que a relação contemporânea da oficialidade católica com João Maria não é tão conflituosa quanto se ressaltou na literatura e que o movimento legitimador de João Maria ocorre também a partir da hierarquia religiosa, especialmente aquela vinculada à Igreja Progressista, conhecida também como Igreja ou Catolicismo da Libertação, e as Pastorais Sociais (como CPT). Isso ficou evidenciado no apoio aberto (ou mais discreto) de parte do clero às atividades religiosas não institucionais, especialmente devocionais e penitenciais envolvendo João Maria e da apropriação deste em lutas promovidas pelas pastorais e movimentos sociais.

Muitas lideranças, partidos políticos e movimentos reivindicatórios, com características populares, democráticas, autônomas e inspiradas numa perspectiva cristã da "opção pelos pobres", surgiram no âmbito desta Igreja Progressista. Para fundamentar um "fazer político" ou a intermediação entre "fé e vida" junto às populações, esta Igreja e os movimentos sociais de Santa Catarina promoveram, a partir da década de 1980, uma releitura da Guerra do Contestado e das populações envolvidas nela. Refletiram sobre a perspectiva "oficial" e propuseram pensar nela como um movimento legítimo e organizado de camponeses pelo acesso à terra e por condições de trabalho nela. Além disso, estimularam a leitura da história a partir dos protagonistas, no caso, os camponeses, mas também de líderes como João Maria. Esta interpretação transformou o caráter dos protagonistas, que tinham sido considerados anteriormente como "perdedores", em símbolos da luta dos movimentos sociais atuais. Para tanto, esses movimentos, nomeadamente a CPT e o MST, lançam mão de recursos pedagógicos, discursos, mitos, rituais, místicas, símbolos (como João Maria e a cruz de cedro), organizam eventos, como romarias, caminhadas, marchas e celebrações, para viabilizar e implementar os valores e princípios reivindicativos, especialmente junto à população-alvo, mas também junto à população em geral e ao Estado. Disto, observei um movimento duplo de legitimimação - ao mesmo tempo que João Maria foi legitimado por lideranças sociais e pela Igreja da Libertação, instrumentalizou os movimentos reivindicatórios, as lideranças e as organizações. Neste movimento, João Maria passou por um processo ressemantizador - de santo legitimado, passou a líder político atualizado.

Uma forma diferenciada de legitimidade política de João Maria foi possibilitada por um projeto governamental na década de 1980. Numa tentativa de construir uma identidade catarinense, o governador do estado de Santa Catarina buscou, no Movimento do Contestado e naquele que denominou de "homem do Contestado", o caboclo/jagunço, uma alternativa para representar o "homem catarinense". Durante sua gestão (1983-1986), estimulou várias ações ligadas ao resgate da memória, na ótica deste governante, daquele conflito 
armado e de seus protagonistas. Na prática, a memória do Contestado foi folclorizada por esse governo e pelo Projeto do Contestado, congelando a luta dos sertanejos no passado e negando qualquer vínculo destes com os dilemas sociais contemporâneos. Esta perspectiva é diferente daquela assumida pela Igreja Progressista, pastorais e movimentos sociais e posteriormente pelo próprio Esperidião Amin, qual seja, o fortalecimento dos movimentos reivindicatórios atuais a partir da memória do Contestado. É inegável, no entanto, que esta legitimidade fortaleceu ou foi fortalecida pela outra, empreendida pelos movimentos sociais no mesmo período. Dessa maneira, não parece estranho que hoje se fale mais abertamente sobre a Guerra do Contestado, tão silenciada nas décadas seguintes aos combates, ou sobre João Maria, configurado também como símbolo da luta pela terra, além de profeta e santo.

Os discursos expressivos a respeito de João Maria se popularizaram em Santa Catarina especialmente na década de 1980, período marcado pela abertura política, surgimento de diversos movimentos sociais e pelo projeto governamental. A observação de obras arte, instalações, acervo de museus, grutas/santuários, músicas, poesia, dança, peças teatrais e cinema permitiume constatar que os discursos explicitam basicamente duas caracterizações de João Maria: como liderança religiosa e política ou como santo. Os sinais destes reconhecimentos, encontrados em grutas, santuários, capitéis e capelas, indicam que sua imagem e símbolo são constantemente apropriados nas lutas coletivas por justiça social ou particulares no controle da indeterminação do mundo.

De maneira geral, os discursos orais, escritos, performáticos e expressivos a respeito de João Maria em Santa Catarina na contemporaneidade foram construídos pelos joaninos na sua cultura histórica, possuem temporalidade e expressam algo. No entanto, reforçando o processo sugerido pela hermenêutica de Ricoeur, observei que os discursos dos joaninos, embora formulados e expressados a partir das referências históricas dos joaninos e ostensivas da interlocução, afastam-se, num segundo momento, destas referências, ultrapassam o caráter individual para assumir uma dimensão inter-humana e histórica e são objetivados, autonomizam-se e tornam-se "obras abertas" a leituras e múltiplas interpretações. Nesse contexto, percebo que é o próprio discurso autonomizado dos joaninos, a princípio a respeito de João Maria, que serviu como mecanismo de legitimação deste (como divindade, profeta, santo, guia de procedimentos de cura ou símbolo da luta pela terra), dos discursos atribuídos a ele, dos próprios discursantes (joaninos) e de sua cultura histórica. Com base nesta legitimação, é que os discursos a respeito de João Maria se tornam apropriados para interpretação do mundo dos joaninos, para controlar a indeterminação do mundo, para anunciar e acabar com o mal, reagir contra aquilo que não está de acordo com sua cultura, estimular a luta política ou anunciar o mundo desejado. 


\section{NOTAS}

${ }^{1}$ Comunicação apresentada no "Simpósio sobre o Centenário do movimento do Contestado - História, Memória, Sociedade e Cultura no Brasil Meridional (1912-2012)", realizado em Florianópolis, na Universidade Federal de Santa Catarina (UFSC), entre 29 maio 2012 e 01 jun. 2012.

2 Estou considerando discursos de homens e mulheres com diversas origens, contextos, idades e religiosidades.

${ }^{3}$ Dentre inúmeros, gostaria de destacar os trabalhos de pesquisa realizados por: OLIVEIRA, Célio. A construção e a permanência do mito de João Maria de Jesus na região do contestado, Santa Catarina. Dissertação (Mestrado em ?), UFGRS, Porto Alegre, 1992; FACHEL, José F. Monge João Maria: recusa dos excluídos. Porto Alegre: EdUFRGS/ Florianópolis: EdUFSC, 1995; CREPEAU, Robert R. Le Saint auxiliaire des chamanes: La figure de "Saint" João Maria d'Agostinho chez les Kaingang du Brésil méridional. Quebec: Département d'anthropologie/ Université de Montreal, 2004; GOES, César Hamilton Brito. Nos caminhos do Santo Monge: religião, sociabilidade e lutas sociais no sul do Brasil. Tese (Doutorado em Sociologia), UFRGS, Porto Alegre, 2007; KARSBURG, Alexandre de O. O eremita do Novo Mundo: a trajetória de um italiano pelos sertões brasileiros no século XIX. Revista Eletrônica de História do Brasil, Juiz de Fora, v. 9, n. 2, jul./dez. 2007.

${ }^{4}$ RICOEUR, Paul. Do texto à acção: Ensaios de Hermenêutica II. Porto: Rés, 1989.

${ }_{5}^{5}$ RICOEUR, Paul. O conflito de interpretações. Rio de Janeiro: Imago, 1978 [1969]. p. 41.

${ }^{6}$ A Comunidade Cafuza é um grupo étnico formado pela miscigenação entre negros e índios e "partilha de maneira mais ampla a cultura cabocla própria dos segmentos marginalizados da população camponesa 'nativa' de Santa Catarina". MARTINS, Pedro. Comunidade Cafuza de José Boiteux: História e antropologia da apropriação da terra Tese (Doutorado em Antropologia Social), USP, São Paulo, 2001. Este grupo constituiu-se no final do século XIX e, depois de ter participado da Guerra do Contestado, passou a integrar o contingente de expropriados da terra. Depois de quase um século de perambulação conquistou sua propriedade na localidade de Alto Rio Laeiscz, município de José Boiteux/SC, em novembro de 1992.

7 RICOEUR, 1989, op. cit.

8 WEBER, Max. Sociologia da Religião. Economia e Sociedade. 3. ed. Brasília: UnB, 2000. v. 1 .

9 RICOEUR, 1989, op. cit.

${ }^{10}$ VELHO, Otávio. Besta-Fera: recriação do mundo. Rio de Janeiro: Relume-Dumara, 1995.

${ }^{11}$ GEERTZ, Clifford. Interpretação das culturas. Rio de Janeiro: Zahar, 1978.

${ }^{12}$ RICOEUR, 1989, op. cit.

${ }^{13}$ Idem, 1978, p. 15. Para esse autor, interpretação "é o trabalho de pensamento que consiste em decifrar o sentido oculto no sentido aparente, em desdobrar os niveis de significação implicados na significação literal. Guardo assim a referência inicial à exegese, isto é, à interpretação dos sentidos ocultos. Símbolo e interpretação tornam-se, assim, conceitos correlativos”.

${ }^{14}$ RICOEUR, 1989, op. cit.

${ }^{15}$ VELHO, op. cit.

${ }^{16}$ GEERTZ, op. cit. 
${ }^{17}$ DICKIE, Maria Amelia S. Afetos e circunstâncias. Tese (Doutorado em Ciência Social), USP, São Paulo, 1996.

${ }^{18}$ RICOEUR, 1989, op. cit.

${ }^{19}$ Trata-se de imigrantes ou descendentes de imigrantes de origem europeia (especialmente alemães e italianos) que participaram do processo de colonização nos estados do Sul do Brasil, entre os séculos XIX e XX.

${ }^{20}$ A ideia de "comunidade remanescente de quilombos" passou a ser veiculada no Brasil, principalmente no final da década de 80 , "para se referir às áreas territoriais onde passaram a viver os africanos e seus descendentes no período de transição que culminou com a abolição do regime de trabalho escravo, em maio de 1888. [...] As terras dos quilombos foram consideradas parte do patrimônio cultural desses grupos negros e enquanto tais deveriam ser alvo de proteção por parte do Estado". LEITE, I. B.; FERNANDES, R. C. Fronteiras territoriais e questões teóricas: a antropologia como marco. Boletim Informativo do Nuer, Florianópolis, v. 3, n. 3 , 2006.

${ }^{21}$ Denominação positiva assumida por algumas pessoas que residem em Taquaruçu (município de Fraiburgo), antiga "Cidade Santa", embora em passado recente ou em outros contextos tenha um significado pejorativo.

${ }^{22}$ A noção de caboclo, cultura cabocla e "de origem cabocla" estão inspiradas em Martins, 2001.

${ }^{23} \mathrm{O}$ termo evangélico é genérico e serve para referir-se a todos os cristãos protestantes vinculados a diversas denominações religiosas. PIERUCCI, Antônio F. Apêndice: as religiões no Brasil. In: HELLERN, V. et al. O livro das religiões. São Paulo: Cia da Letras, 2000.

${ }^{24}$ Nas primeiras décadas do século XX, começaram a chegar ao Brasil igrejas protestantes pentecostais. As igrejas pentecostais diferenciam-se das outras igrejas protestantes (guardadas as diferenças) por conservar um estilo de culto fortemente emocional, voltado para o êxtase, com papel de destaque para a glossolalia, o exorcismo e o milagre, visados sempre resultados palpáveis a serem experimentados de imediato. PIERUCCI, op. cit., p. 288. Neste trabalho utilizo o termo pentecostal para me referir aos cristãos vinculados às diversas denominações pentecostais.

${ }^{25}$ STEIL, Carlos A. Catolicismo e memória no Rio Grande do Sul. Debates do NER, Porto Alegre, PPGAS/UFRGS, n. 5, 2004.

${ }^{26}$ VELHO, op. cit., sugere que o holismo deve ser entendido apenas como uma tendência (em certas situações como dominante), mas não "como uma anulação ou exclusão da individualidade em qualquer contexto".

${ }^{27}$ DUMONT, Louis. O individualismo: uma Perspectiva Antropológica da Ideologia Moderna. Rio de Janeiro: Rocco, 1985; DUMONT, Louis. Homo Hierarchicus: o sistema das castas e suas implicações. São Paulo: Edusp, 1992 [1966]; DA MATTA, Roberto. Você sabe com quem está falando? Um ensaio sobre a distinção entre indivíduo e pessoa no Brasil. In:

Carnavais malandros e heróis: para uma Sociologia do dilema brasileiro. 5. ed. Rio de Janeiro: Guanabara, 1990.

${ }^{28}$ Noções inspiradas em: WOORTMANN, Klass. Reconsiderando o parentesco. Anuário antropológico 76. Rio de Janeiro: Tempo Brasileiro, 1977; MENDRAS, Henri. Grupos domésticos. In: Sociedades camponesas. Rio de Janeiro: Zahar, 1978; AUGÉ, Marc. Os domínios do parentesco. Lisboa: Edições 70, 1978. 
${ }^{29}$ MAUSS, Marcel. Ensaio sobre a dádiva. Sociologia e Antropologia. São Paulo: Epu/Edusp, $1974[1902 / 3]$. v. 1

${ }^{30}$ Guardadas as diferenças de abordagem, sobre os desdobramentos das relações de compadrio em contextos rurais e urbanos, ver especialmente: ARANTES, Antônio A. Pais, padrinhos e o espírito santo. In: ARANTES, A. A. et al. Colcha de retalhos: estudos sobre a família no Brasil. 3 ed. São Paulo: Unicamp, 1994; MONTEIRO, op. cit.; WOORTMANN, Klass. Com parente não se neguceia". O campesinato como ordem moral. Anuário Antropológico 87. Rio de Janeiro: Tempo Brasileiro; Brasília:UNB, 1990; FONSECA, Cláudia e BRITES, Jurema. O batismo em casa: uma prática popular do Rio Grande do Sul. Cadernos de Estudos do Programa de Pós-Graduação em Antropologia Social, Porto Alegre, PPGAS/UFRGS, n. 14, 1988.

${ }^{31}$ A partir desta constatação, sugere-se que o sacramento do batismo não se configura apenas como uma significação religiosa, mas também como realização de interesses sociais e econômicos para além das relações familiares. SERPA, Élio C. Igreja e poder em Santa Catarina. Florianópolis: EdUFSC, 1997.

${ }^{32}$ Lembrando que a reciprocidade só ocorre entre pessoas (não indivíduos). WOORTMANN, op. cit.

${ }^{33}$ STEIL, op. cit.

${ }^{34}$ MONTEIRO, op. cit. O termo "rústico" foi empregado na década de 50 por Cândido (1987), fazendo referência à cultura camponesa e cabocla. A partir daí, este termo é utilizado por Monteiro (1974) referindo-se à religiosidade das populações caboclas do planalto catarinense.

${ }^{35}$ Sobre a Igreja da Libertação ou Catolicismo libertador ver também: OLIVEIRA, Pedro A. R. O Catolicismo: das CEBs à Renovação Carismática. Teoria e Sociedade: passagem de milênio e pluralismo religioso na sociedade brasileira, Belo Horizonte, Departamento de Ciência Política e de Sociologia e Antropologia/UFMG, número especial, maio 2003.

${ }^{36}$ LOCKS, Geraldo A. identidade dos agricultores familiares brasileiros de São José do Cerrito. Dissertação (Mestrado em Antropologia Social) UFSC, Florianópolis, 1998.

${ }^{37}$ Há outras formas de classificar os vários catolicismos. Apenas para exemplificar, OLIVEIRA, op. cit., percebe quatro modelos na trajetória do catolicismo brasileiro: 1) Catolicismo da salvação individual (religião de compensação), 2) Catolicismo popular (religião de compensação), 3) Catolicismo da Libertação (anos 70 e 80, religião da redenção) e, 4) Catolicismo Carismático (mundo moderno e pós-moderno, década de 90, religião de aperfeiçoamento). Ao analisar o processo histórico do catolicismo no Rio Grande do Sul (aliado ao processo histórico mais amplo), STEIL, op. cit., observa uma divisão semelhante à anterior: catolicismo moderno de origem ibérica e catolicismo tradicional (entre século XVI e XVIII), catolicismo de imigração (final do século XIX e início do XX), catolicismo romanizado (segunda metade do século XIX), catolicismo libertador (década de 70 e 80), catolicismo carismático (década de 90) e catolicismo difuso e cultural.

${ }^{38}$ STEIL, op. cit.

${ }^{39}$ OLIVEIRA, Pedro A. R. O catolicismo: das CEBs à renovação carismática. Teoria e Sociedade: Passagem de Milênio e Pluralismo Religioso na Sociedade Brasileira, n. especial, maio, 2003. Belo Horizonte: Departamento de Ciência Política e de Sociologia e Antropologia/ UFMG, 2003.

${ }^{40}$ Sobre a formação do catolicismo catarinense e brasileiro, destaco SERPA, Élio C. Igreja e poder em Santa Catarina. Florianópolis: EdUFSC, 1997. 
${ }^{41}$ SERPA, op. cit.

${ }^{42}$ MONTEIRO, op. cit. p. 84.

${ }^{43}$ Comunidade está sendo usada aqui para definir o conjunto de pessoas ou famílias ligadas, pela cultura histórica, a uma organização religiosa, não necessariamente institucional.

${ }^{44}$ Tomo ritual como discurso simbólico, apropriado para transmitir, reproduzir e legitimar sistemas de valores, mostrar como alguns elementos podem ser transformados em símbolos que edificam e solidificam a identidade dos participantes, instituem ordem nas relações sociais, amenizam incertezas e inseguranças, e, com isso, também constroem realidades. MIRANDA, Júlia. Carisma, sociedade e politica: novas linguagens do religioso e do político. Rio de Janeiro: Relume Dumará, 1999. Além disso, penso nos rituais como discursos performáticos porque possibilitam ao sujeito experimentar, viver, criar, resolver, construir e interpretar símbolos, crenças, emoções, sentimentos e conflitos. TURNER, Victor. O processo ritual. Petrópolis: Vozes, 1974.

${ }^{45}$ Este é o nome dado à pessoa adulta (homem ou mulher) que coordena o batizado não eclesial, função frequentemente assumida por aquele que, notadamente, conhece as regras ritualísticas tradicionais necessárias.

${ }^{46}$ Nesse caso, o padrinho seria representado por meio de uma imagem.

${ }^{47}$ Este processo ocorre a partir do investimento de uma autoridade na transformação do caráter da água - de água comum para "água sagrada". Antes do Concílio Vaticano II, abençoar a água significava retirar dela o domínio do maligno e assim habilitá-la para realizar batizados, abençoar pessoas, lugares e objetos. Após este concílio, a Igreja abençoa a água para louvar a Deus e colocar em evidência a dimensão salvífica da mesma. GOEDERT, Valter M. O simbolismo da água. Revista Encontros Teológicos, Florianópolis, ano 19/1, n. 37, 2004.

${ }^{48}$ MAUSS, op. cit.

${ }^{49}$ Ouvi depoimentos de pessoas que se deslocaram mais de 300 quilômetros para buscar esta água.

${ }^{50}$ Este mesmo procedimento ocorre entre as populações rurais catarinenses analisadas por: BLOEMER, Neusa M. S. Brava gente brasileira. Florianópolis: Cidade Futura, 2000; RENK, Arlene. A luta da erva: um ofício étnico no oeste catarinense. Chapecó: Grifos, 1997; LOCKS, Geraldo A. identidade dos agricultores familiares brasileiros de São José do Cerrito. Dissertação (Mestrado em Antropologia Social), UFSC, Florianópolis, 1998.

${ }^{51}$ Estes aspectos foram observados por FONSECA; BRITES, 1988, op. cit. entre grupos populares urbanos da região de Porto Alegre/RS.

${ }^{52}$ Recurso pedagógico utilizado milenarmente pela Igreja Católica para ensinar as mensagens do cristianismo.

${ }^{53}$ A novena é composta por um ritual que será repetido nove vezes (dias, semanas, meses).

${ }^{54}$ Recebi informações de prática deste ritual em outros municípios da Serra Catarinense e no Oeste de Santa Catarina.

${ }^{55}$ A prática da benzedura e do curanderismo ocorre no interior de diversos segmentos religiosos e estes "especialistas" apropriam-se de saberes de diversas religiões, como a católica, pentecostal, kardecista, umbandista e esotérica para orientar sua prática. BRANDÃO, Carlos, R. Festim dos bruxos. Campinas, São Paulo: Unicamp/Ícone, 1987.

${ }^{56}$ Estes especialistas são classificados como "mediadores" (MOURÃO, Laís. Contestado: a gestação social do messias. Cadernos Ceru, São Paulo, Humanitas FFLCH/USP, n. 7, 1975); 
como "especialistas para o controle sobrenatural" (QUEIROZ, Maurício V. Messianismo e conflito social: a Guerra Sertaneja do Contestado 1912 - 1916. 2. ed. São Paulo: Ática, 1977); e como "agentes religiosos populares"(BRANDÃO, Carlos R. Os deuses do povo. São Paulo: Brasiliense, 1980).

${ }^{57}$ MONTEIRO, op. cit.

${ }^{58}$ SERPA, Élio C. Igreja e poder em Santa Catarina. Florianópolis: EdUFSC, 1997.

${ }^{59}$ MONTEIRO, op. cit., sugere que a cruz é o símbolo mais importante da "fé rústica" e um escudo mágico contra todos os perigos.

${ }^{60}$ A Comissão Pastoral da Terra surgiu em 1975 durante o Encontro de Pastoral da Amazônia, convocado pela Conferência Nacional dos Bispos do Brasil (CNBB). Informação disponível em: <www.cptnac.com.br>. Acesso em: jan. 2007. Sobre a trajetória da CPT, ver também CAMPIGOTO, José A. Roças, empresas e sonhos: jogos e discursos (ACPT em Santa Catarina). Dissertação (Mestrado em História), UFSC, Florianópolis, 1996; CASTELLS, Alicia N. G. de. A criatividade dos Sem-Terra na construção do habitat: um olhar etnográfico sobre a dimensão espacial do MST. Tese (Doutorado em Ciências Humanas), UFSC, Florianópolis, 2001.

${ }^{61}$ Informativo da $1^{\text {a }}$ Romaria da Terra - SC, 14.09.1986.

${ }^{62}$ QUINTAIS, Luís. Memoriais da indeterminação do mundo - a coleção de ex-votos do Museu Antropológico de Coimbra. In: QUINTAIS, L. et al. Milagre que Fez. Coimbra: Museu Antropológico da Universidade de Coimbra, 1998.

${ }^{63}$ QUINTAIS, op. cit.

${ }^{64}$ MOURÃO, op. cit.

${ }^{65}$ Ideia inspirada em: MARTINS, Pedro. Cabo-verdianos em Lisboa: manifestações expressivas e reconstrução identitária. Revista Horizontes Antropológicos, Porto Alegre, v. 15, n. 31. jan./ jun. 2009, Martins como categoria de análise que deve englobar todas as manifestações capazes de exprimir uma forma ou conteúdo estético aliado a qualquer conteúdo identitário.

${ }^{66}$ Sobre uma leitura crítica e os desdobramentos deste projeto, ver AURAS, Marli. Poder oligárquico catarinense: da guerra dos fanáticos do Contestado à opção pelos pequenos. Tese (Doutorado em Educação), PUCSP, São Paulo, 1991.

${ }^{67}$ GEERTZ, op. cit.

Artigo recebido em novembro de 2012. Aceito em dezembro de 2012. 